\title{
Axisymmetric Thermal Finite Element Analysis of Effects of Intraocular Projector in the Human Eye
}

\author{
John A. Stark ${ }^{* a}$, Craig D. Foster ${ }^{b}$ \& Charles Y $\mathcal{U}^{\circ}$ \\ ${ }^{a}$ Department of Civil and Materials Engineering, University of Illinois at Chicago, IL \\ ${ }^{b}$ Department of Civil and Materials Engineering, University of Illinois at Chicago, IL \\ 'Department of Ophthalmology, Stanford University, $C A$ \\ bttps:// doi.org/10.33697/ ajur.2020.035 \\ Student:jstark.24@uic.edu* \\ Mentor:foster@@uic.edu
}

\begin{abstract}
Millions of people worldwide live with corneal opacity, which continues to be one of the leading causes of blindness. Corneal opacity is treatable. However, the surgical methods for treating this condition, such as corneal transplantation and keratoprosthesis, have many complications. The use of an intraocular projector is a promising approach to treat corneal blindness. Like any device using electrical power, an intraocular projection device produces heat, which could potentially damage eye tissue. Australian and international standards state that there cannot be an increase of temperature of $2{ }^{\circ} \mathrm{C}$ caused by an implanted device. In order to determine if these standards are met, a 2D axisymmetric thermal analysis of the projector in the human eye is conducted in ANSYS Workbench. With the projector operating at its maximum wattage, our analysis shows that an air gap extension within the projector will help maintain the temperature increase below $2{ }^{\circ} \mathrm{C}$.
\end{abstract}

\section{KEYWORDS}

Finite Element Analysis; Eye; Heat Dissipation; Axisymmetric; Thermal Conductivity; Internal Heat Generation; Corneal Blindness; ANSYS; Intraocular Projector

\section{INTRODUCTION}

Disease, infection, wounds, inflammation, scarring, or damage to the cornea of the human eye can cause corneal blindness. These causes can increase corneal opacity, resulting in an indistinct or no image on the retina. ${ }^{1}$ Two well-known surgical procedures for treating corneal blindness are corneal transplantation, also known as keratoplasty, and keratoprosthesis. The process of corneal transplantation generally consists of replacing the damaged cornea with a donor cornea. This surgery has resulted in many complications including the loss of $30-40 \%$ of donor endothelial cells, transplant rejection, astigmatism, choroidal hemorrhage, and many more. ${ }^{2}$ In addition to these complications, there is a shortage of donor corneas, with over $50 \%$ of the world population having no access to a donor cornea. This shortage results in about 13 million people on waitlists for this surgery. ${ }^{3}$ The Boston Keratoprosthesis Type 1 is a common alternative to corneal transplantation considering this shortage of donor corneas. The process of this surgery consists of replacing the damaged cornea with an artificial nonbiologic cornea. However, this artificial cornea's design and material interact with the human eye, resulting in increased risk for infection. ${ }^{4}$

With all the complications, infections from these surgeries, and shortage of donated corneas, an intraocular projector, also known as a micro-camera, has been proposed, with prototypes developed. ${ }^{4}$ The projector takes in video from an external camera, then sends it through a transmission coil, to be later sent to a receiver coil. The receiver transmits this video to a processor to be decoded and sent to a micro-display. The micro-display inside the internal camera projects the image onto the retina. The internal micro-camera consists of a plastic shell, reflector, glass lens, micro-display and LED. 4 As the camera operates, the LED and micro-display create heat. The micro-display stays at a constant power and the LED can be set at different wattages. The larger the wattage, the brighter the picture quality will be displayed on the retina. Generated heat coming from the LED and microdisplay flows through the camera and out into the tissues of the human eye. The closest eye tissue to the camera is the iris. According to the AIMD safety standards (ISO 14708-1:2014 / EN 45502-1:1997), the camera cannot cause an increase in temperature of $2{ }^{\circ} \mathrm{C}$ on any eye tissue, therefore the heat generated by the LED and micro-display needs to be analyzed, especially at the iris. ${ }^{5}$ 
Thermal finite element analysis has already proven useful for a wide variety of applications in the eye. Scott performed one of the earliest thermal finite element analyses of the eye to examine heat flow. ${ }^{6}$ She later used the model to examine the temperature rise due to infrared radiation. ${ }^{7}$ Shabib used finite element analysis to evaluate potential thermal damage from an IR laser. ${ }^{8}$ Jafarbadi $e t$ al. also examined the effects of laser radiation. ${ }^{9}$ Opie et al. used a thermal finite element model of a cat eye to establish that a $5 \times 5$ $\mathrm{mm}$ suprachoroidal heating device cannot dissipate more than $135 \mathrm{~mW}$ through the retina in order to keep the temperature change within $2{ }^{\circ} \mathrm{C} .10$ Gosalia et al. utilized a 3D thermal finite element model of the human head and eye to discover the resulting temperature changes when implanted simulator chips of a retinal prosthesis are surgically placed in the eye. ${ }^{11}$ Through this thermal modeling, Lazzi et al. determined that the smaller chip located in the center of the eye creates a higher temperature rise. ${ }^{12}$ Wessapan and Rattanadecho evaluated potential thermal problems from sauna therapy. ${ }^{13}$ Rafiq and Khanday incorporated blood perfusion and porosity into the thermal model. ${ }^{14}$ Through such studies, the thermal properties of the various tissues in the eye have been well characterized.

The purpose of this study is to provide a preliminary analysis of the impact of the intraocular projector on the temperature inside the eye. A two-dimensional, axisymmetric model is an efficient way to conduct such analysis. The geometry creation, meshing, and analysis are all quicker in two dimensions than three. While the eye is relatively axisymmetric as described by Thompson $e t$ al., ${ }^{15}$ the projector is not. Hence, eventually a three-dimensional model will be developed. The $2 \mathrm{D}$ is useful, however, in examining how changes in the camera model affect the temperature in the iris, as well as verifying the 3D model.

\section{METHODS AND PROCEDURES}

Geometry of 2D Axisymmetric Human Eye Model with Intraocular Projector

Every part of the human eye and projector are modeled in Solidworks. Each part has its own sketch file which are transferred into an assembly file. There are three assembly files, one being without the camera, and two with the camera at different positions in the eye. The assembly files were then transferred into ANSYS Workbench Steady-State Thermal so that a thermal finite element analysis can be conducted in order to test the temperature change amongst the parts of the eye.

A 2D CAD model of the human eye was developed in Solidworks to be axisymmetric about the eye's central axis. The human eye consists of the following parts: cornea, iris, limbus, aqueous humor, ciliary body, cortex lens, nucleus lens, vitreous humor, retina, choroid, sclera, and optic nerve head. The dimensions for each part were based upon the dimensions from the U.S Army

Research Laboratory ${ }^{15}$ and an internal report. ${ }^{16}$

The cornea was modeled first, then the limbus, ciliary body, iris, retina, choroid, optic nerve head (ONH), and iris. For simplicity, the iris was modeled after the exact iris created by Pawar. ${ }^{16}$ The aqueous humor and vitreous humor were then modeled; however, their shape is dependent on the parts surrounding it. The lens of the eye is split into two different regions called the cortex and nucleus lens. Equations from Thompson et al. were used to develop the cortex and nucleus lens. ${ }^{15} \mathrm{~A}$ set of points and spline curve were then used to make the part of the zonule fibers that is flush with the vitreous humor. The other edges of the zonule fibers are made from the parts of the shells of the aqueous humor and ciliary body. ${ }^{15,16}$ Each part was given surface planes and then imported into a Solidworks Assembly file.

The model was then edited so that the zonule fibers, and lens were removed. These parts are physically removed during surgery to make space for the camera. The camera developed by the University of Illinois team was then modeled in Solidworks. The camera is not symmetric about a central axis, so dimensions were changed in order to conserve volume. The camera consists of a casing, reflector, micro-display, LED, and lens. ${ }^{4}$ Each part was modeled in its own Solidworks file and was then imported into the assembly file without the zonule fibers and lens. The vitreous humor was remodeled in according to where the camera would be placed. The changed camera dimensions are displayed in Figure 1. 


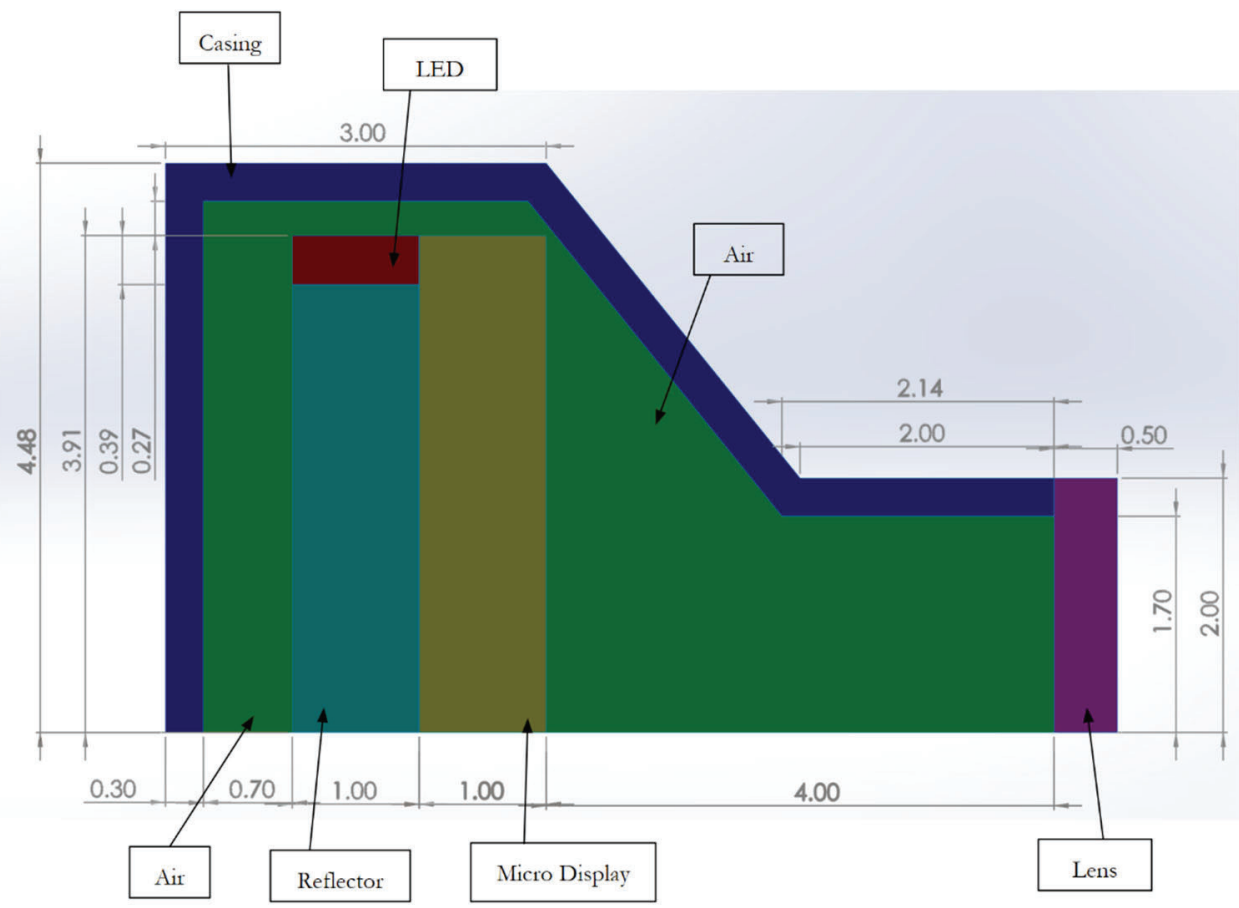

Figure 1. Intraocular Projector (Camera) with Part Descriptions and Dimensions (mm)

The original projector, at its highest power setting for the LED, caused a temperature increase greater than $2{ }^{\circ} \mathrm{C}$ in the iris at a temperature over $39^{\circ} \mathrm{C}$. Several solutions were attempted to improve the thermal dissipation, including changing materials, adding a thermal paste, and adding a conducting material that would dissipate more heat out of the front of the camera. The best solution was to extend the back of the camera $0.5 \mathrm{~mm}$, adding an air gap that acts as an insulator. This insulation pushes more heat out the front and away from the closest living tissues. Only the results from this option and the original projector model are shown in this report. Models 1 and 2 are displayed below in Figure 2 and Figure 3 representing the eye model with the different cameras.

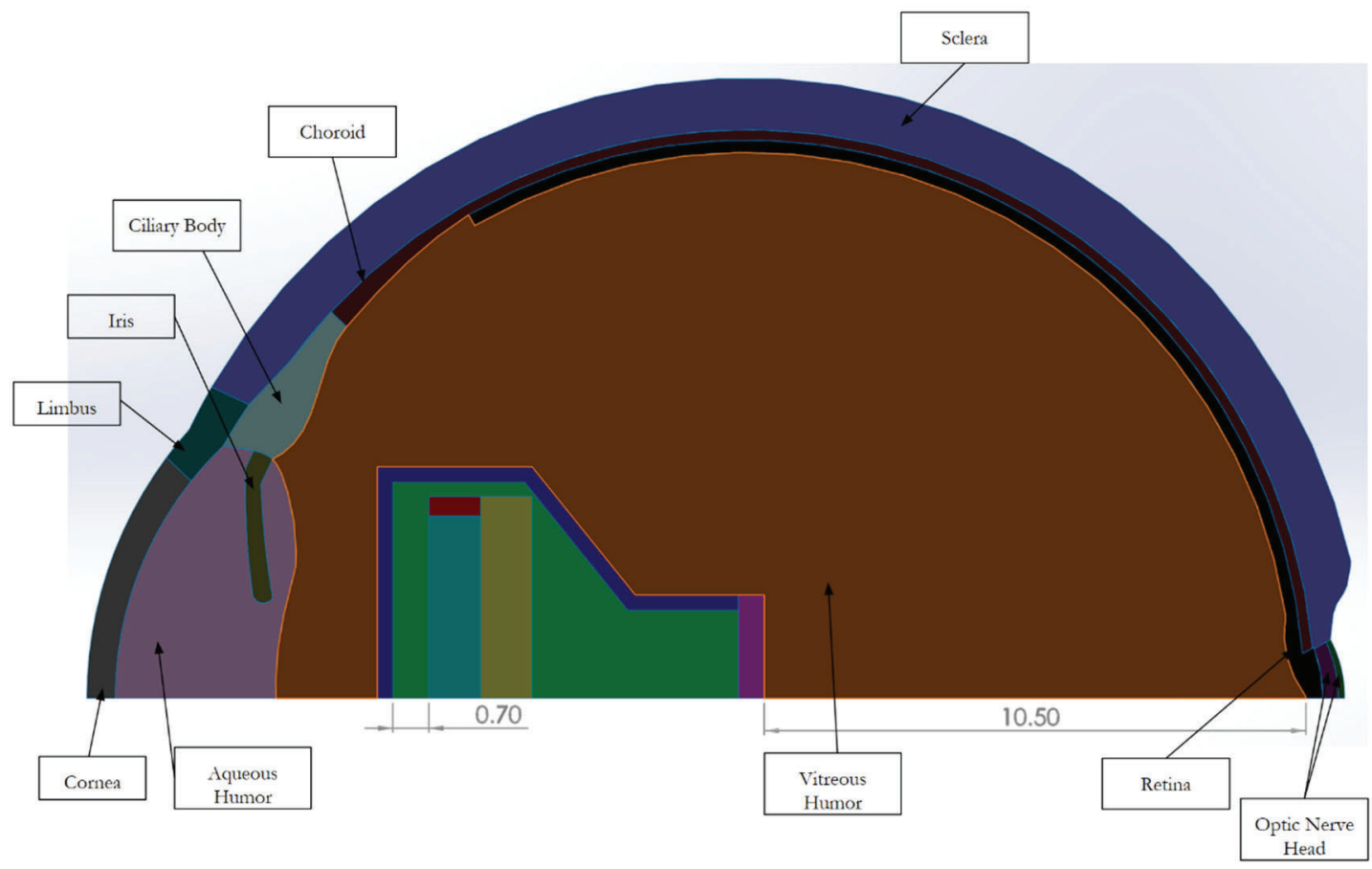

Figure 2. Model 1; Human Eye with Part Descriptions, Original Projector, and Dimensions (mm) 


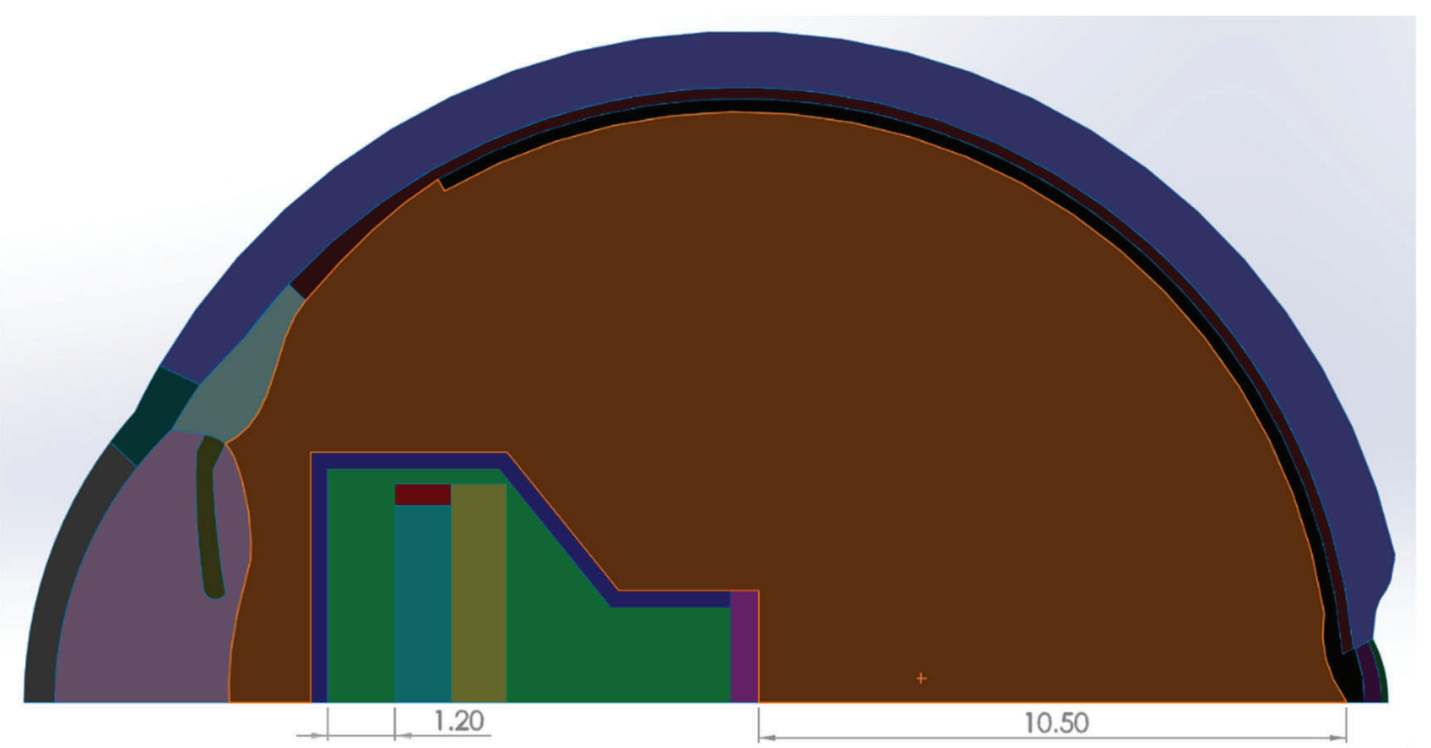

Figure 3. Model 2; Human Eye with Projector and 0.5 mm Air Gap Extension (mm)

\section{Steady State Thermal Analysis}

Models 1 and 2 were converted into IGS files which were then transferred into ANSYS Workbench. Steady-State Thermal Analyses were created for the assembly files. For the import geometry settings, the analysis was set to $2 \mathrm{D}$ with only surface bodies allowed to be imported. The $2 \mathrm{D}$ behavior for geometry was also set to axisymmetric.

\section{Material Properties of Eye and Projector Parts}

Each material in the eye and camera has a specific thermal conductivity value associated with it. Thermal conductivity values measure how easily heat is transferred through the eye. Therefore, they are important to accurately assess how quickly and in what directions heat will dissipate from the eye. The PMMA and ABS plastics can have somewhat different compositions and manufacturing conditions, and therefore have a range of thermal conductivity values. The values for air and glass were taken directly from ANSYS. The thermal conductivity values are displayed in Table 1.

\begin{tabular}{|c|c|c|}
\hline Part & Thermal Conductivity $\left(\mathbf{W} / \mathbf{m}^{\circ} \mathbf{C}\right)$ & Reference Number \\
\hline Cornea & 0.58 & $\mathbf{1 0}$ \\
\hline Sclera & 0.58 & $\mathbf{1 0}$ \\
\hline Choroid & 0.6 & $\mathbf{1 7}$ \\
\hline Iris & 1.0042 & $\mathbf{1 7}$ \\
\hline Optic Nerve Head (ONH) & 1.0042 & $\mathbf{1 0}$ \\
\hline Retina & 0.565 & $\mathbf{1 7}$ \\
\hline Aqueous Humor & 0.58 & $\mathbf{1 7}$ \\
\hline Ciliary Body & 0.498 & $\mathbf{1 7}$ \\
\hline Limbus & 0.58 & $\mathbf{1 9}$ \\
\hline Saline Solution & 0.603 & $\mathbf{2 0}$ \\
\hline Air & 0.0242 & $\mathbf{2 1}$ \\
\hline PMMA & $0.1922-0.1986$ & \\
\hline ABS Plastic & $0.14-0.21$ & \\
\hline Glass & 0.8 & \\
\hline
\end{tabular}

Table 1. Thermal Conductivity Values of Eye and Camera Parts

The eye parts were assigned their corresponding thermal conductivity values in ANSYS. During the procedure of inserting the camera into the eye, the vitreous humor will be replaced with saline solution, so that area was given the thermal conductivity value of saline solution. The LED and Reflector are made of ABS plastic. Considering this thermal conductivity value has a range, the decision was made to make the value $0.175 \mathrm{~W} / \mathrm{m}{ }^{\circ} \mathrm{C}$ which is the midpoint of this range of these values. Analysis was also 
conducted at both extremes for the range of these values for ABS plastic, but there was no significant change in temperature of any part of the eye tissue. The micro-display and camera lens were given the material of glass. Lastly, the camera casing was given the material of PMMA. PMMA also has a range of thermal conductivity values, and these values are linearly related to temperature. ${ }^{20}$ The value used in this study was $0.19289 \mathrm{~W} / \mathrm{m}{ }^{\circ} \mathrm{C}$.

\section{Meshing}

The meshing for Models 1 and 2 were generated in ANSYS. To simplify the meshing process, Automatic Mesh Defeaturing was turned to Off. Model 1 consists of 5,270 nodes and 1,469 elements. Model 2 consists of 5,161 nodes and 1,430 elements. The mesh for both models were not further refined because the mesh was adequate for the analysis to be performed. The meshing for each model is shown in Figure 4.

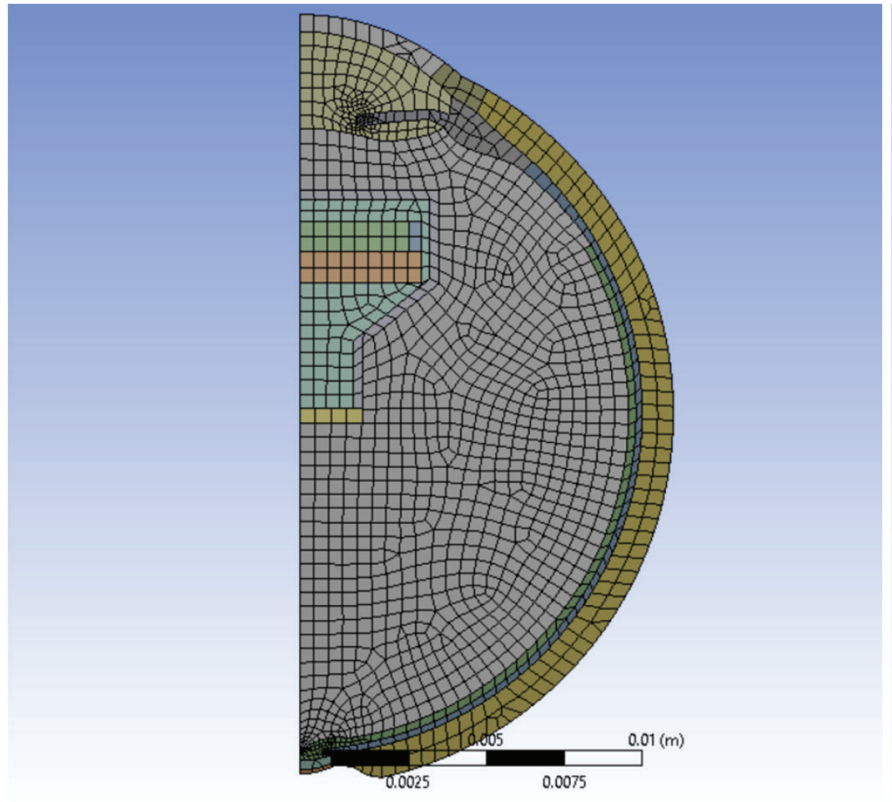

(a)

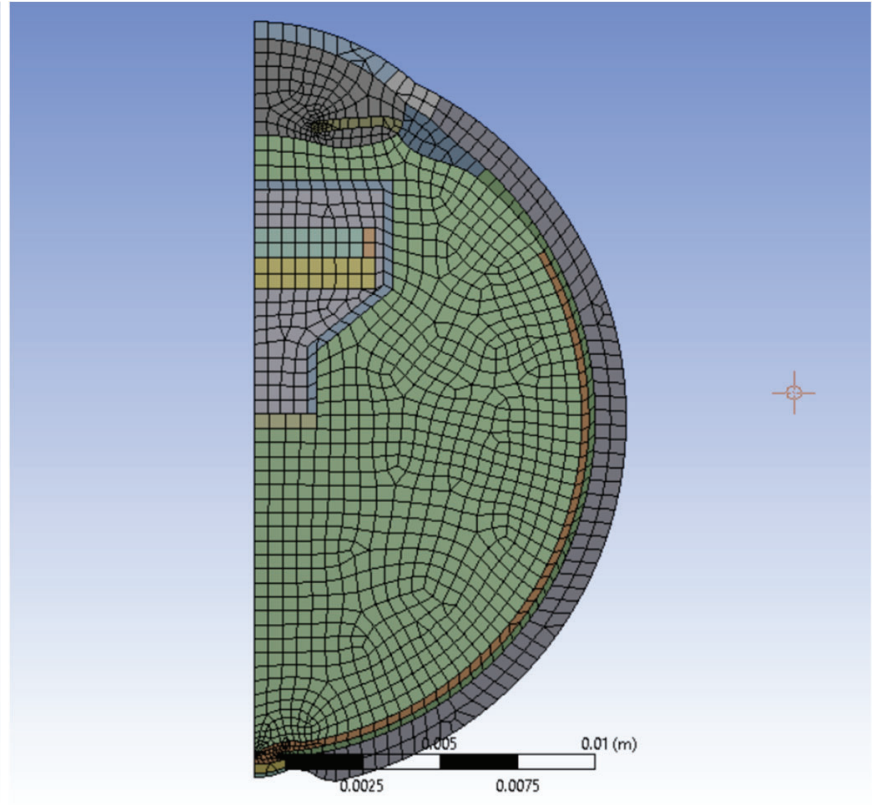

(b)

Figure 4. (a) Meshing for Model 1; (b) Meshing for Model 2

\section{Boundary Conditions}

The thermal conditions at the boundary of the eye vary by location. A temperature of $37{ }^{\circ} \mathrm{C}$ is applied on the surface of the sclera because normal body temperature is $37^{\circ} \mathrm{C} .{ }^{6}$ Convection of $37{ }^{\circ} \mathrm{C}$ with film coefficient $65 \mathrm{~W} / \mathrm{m}^{2}{ }^{\circ} \mathrm{C}$ is applied on the surface of the sclera as well..$^{10}$ An external temperature of $40^{\circ} \mathrm{C}$ is chosen for the cornea and limbus to represent an extreme outside temperature. A film coefficient $10 \mathrm{~W} / \mathrm{m}^{2}$ is also applied. ${ }^{6}$ Outward heat flux of $40 \mathrm{~W} / \mathrm{m}^{2}$ and radiation with emissivity of 0.975 is applied on the surface of the cornea and limbus as well. ${ }^{6}$ Internal heat generation is applied to the bodies of the micro-display and LED because these parts are a power source and are generating heat. The input for internal heat generation in ANSYS is in $\mathrm{W} / \mathrm{m}^{3}$. The micro-display will only be set at $25 \mathrm{~mW}$ for this analysis; however, the LED will be set at four different wattages of 25 $\mathrm{mW}, 50 \mathrm{~mW}, 75 \mathrm{~mW}$, and $100 \mathrm{~mW}$. Using these wattages and the geometry of the parts of the camera, the internal heat generation values were calculated and are shown in Table 2.

\begin{tabular}{|c|c|c|c|c|c|}
\hline \multirow[b]{2}{*}{ Part } & \multirow[b]{2}{*}{ Volume $\left(\mathrm{m}^{3}\right)$} & \multicolumn{4}{|c|}{ Internal Heat Generation $\left(\mathrm{W} / \mathrm{m}^{3}\right)$} \\
\hline & & $25 \mathrm{~mW}$ & $50 \mathrm{~mW}$ & $75 \mathrm{~mW}$ & $100 \mathrm{~mW}$ \\
\hline LED & $9.00 \times 10^{-9}$ & $2.78 \times 10^{6}$ & $5.56 \times 10^{6}$ & $8.33 \times 10^{6}$ & $1.11 \times 10^{7}$ \\
\hline Micro-Display & $4.80 \times 10^{-8}$ & $5.21 \times 10^{5}$ & & & \\
\hline
\end{tabular}

Table 2. Internal Heat Generation of Micro-Camera Parts at Different Wattages

The LED is set at these four wattages because as there is more power, there is more heat flowing through the eye and thereby causing a larger increase in temperature of an eye tissue. $25 \mathrm{~mW}$ is the minimum power that the LED will be set at in order for the camera to work properly. The maximum power at which the LED can be set is $100 \mathrm{~mW}$. This setting provides the brightest picture to the retina. The goal is to pinpoint which wattage does not cause an increase of $2{ }^{\circ} \mathrm{C}$ to stay within AIMD standards. 


\section{RESULTS AND DISCUSSION}

The analysis conducted in ANSYS was completed by solving for the final temperatures in Models 1 and 2 . The final solutions for the analysis at $25 \mathrm{~mW}, 50 \mathrm{~mW}$, and $75 \mathrm{~mW}$ did not display a temperature over $39{ }^{\circ} \mathrm{C}$, which is $2{ }^{\circ} \mathrm{C}$ above the original temperature of the eye at $37^{\circ} \mathrm{C}$, at any eye tissue for these two models. At $100 \mathrm{~mW}$ the iris does exceed over $39^{\circ} \mathrm{C}$ for Model 1 which does not abide by AIMD standards. The final solution for Model 1 is portrayed in Figure $\mathbf{5}$.

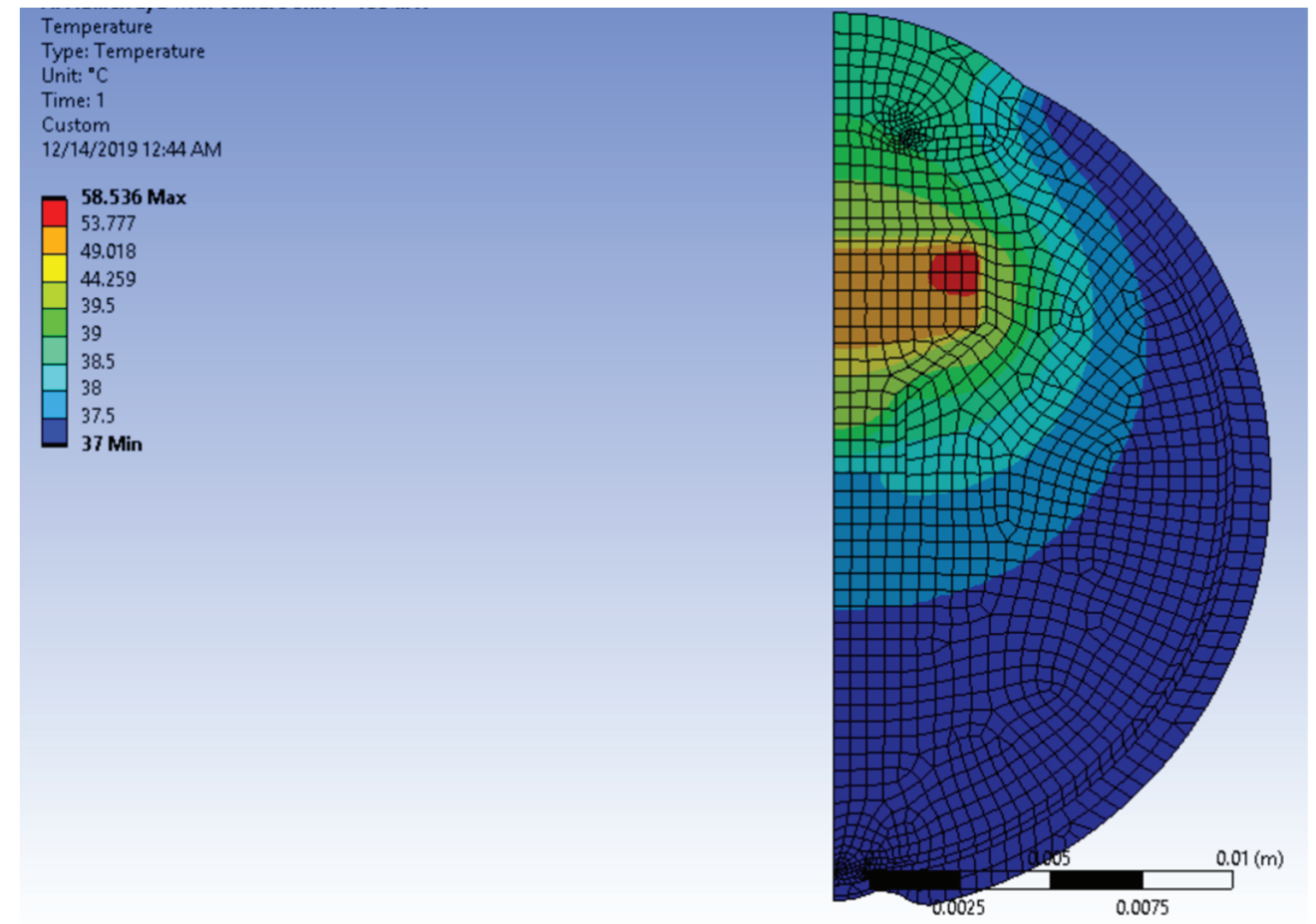

Figure 5. Model 1 Analysis Temperature Solution at $100 \mathrm{~mW}$

The major heating issue is that too much heat escapes from the back of the camera and heats the iris, as shown in the heat flux plot in Figure 6.

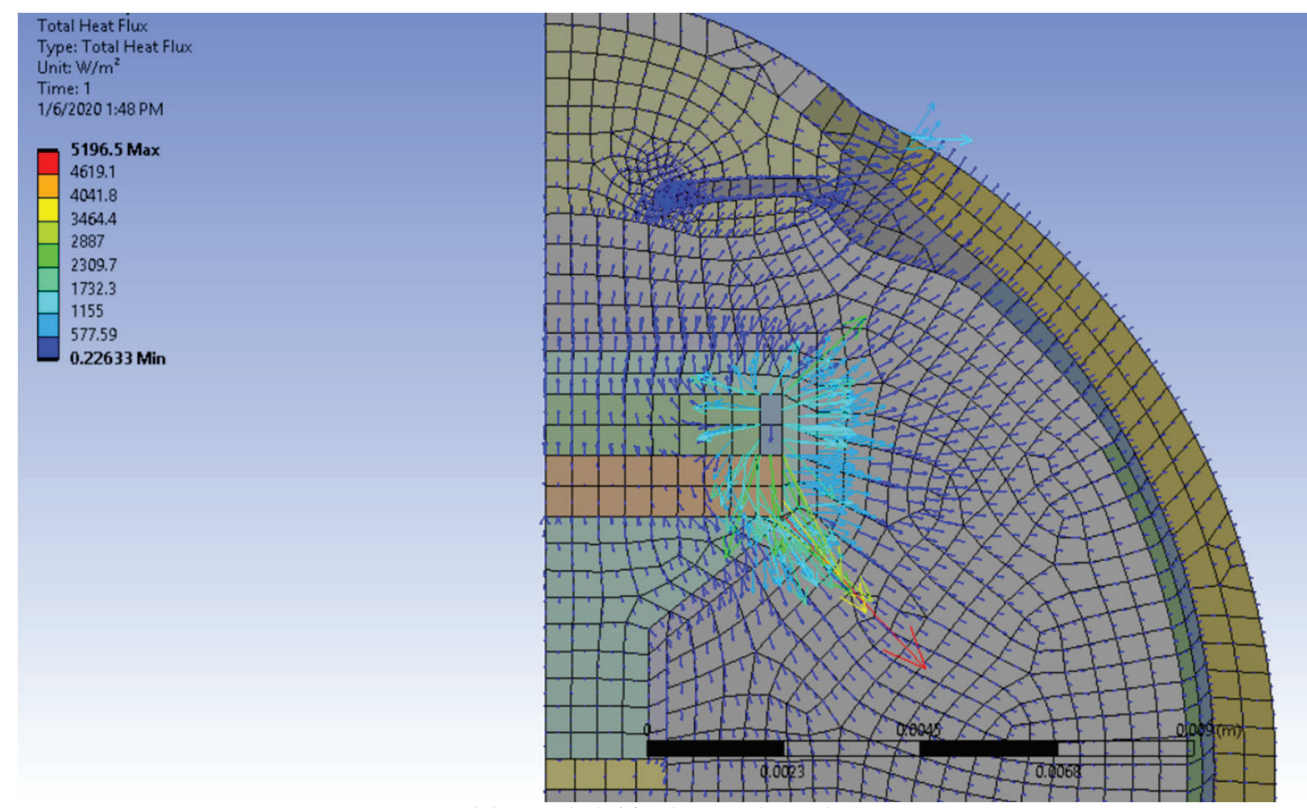

Figure 6. Model 1 Analysis Total Heat Flux Solution at $100 \mathrm{~mW}$ 
Model 2 contains an extended air gap of $0.5 \mathrm{~mm}$ within the camera. Air is a great insulator if it can be contained and with this update in geometry compared to Model 1, iris temperatures were kept below $39^{\circ} \mathrm{C}$ at all wattages. Figure 7 displays the solution for Model 2 at $100 \mathrm{~mW}$.

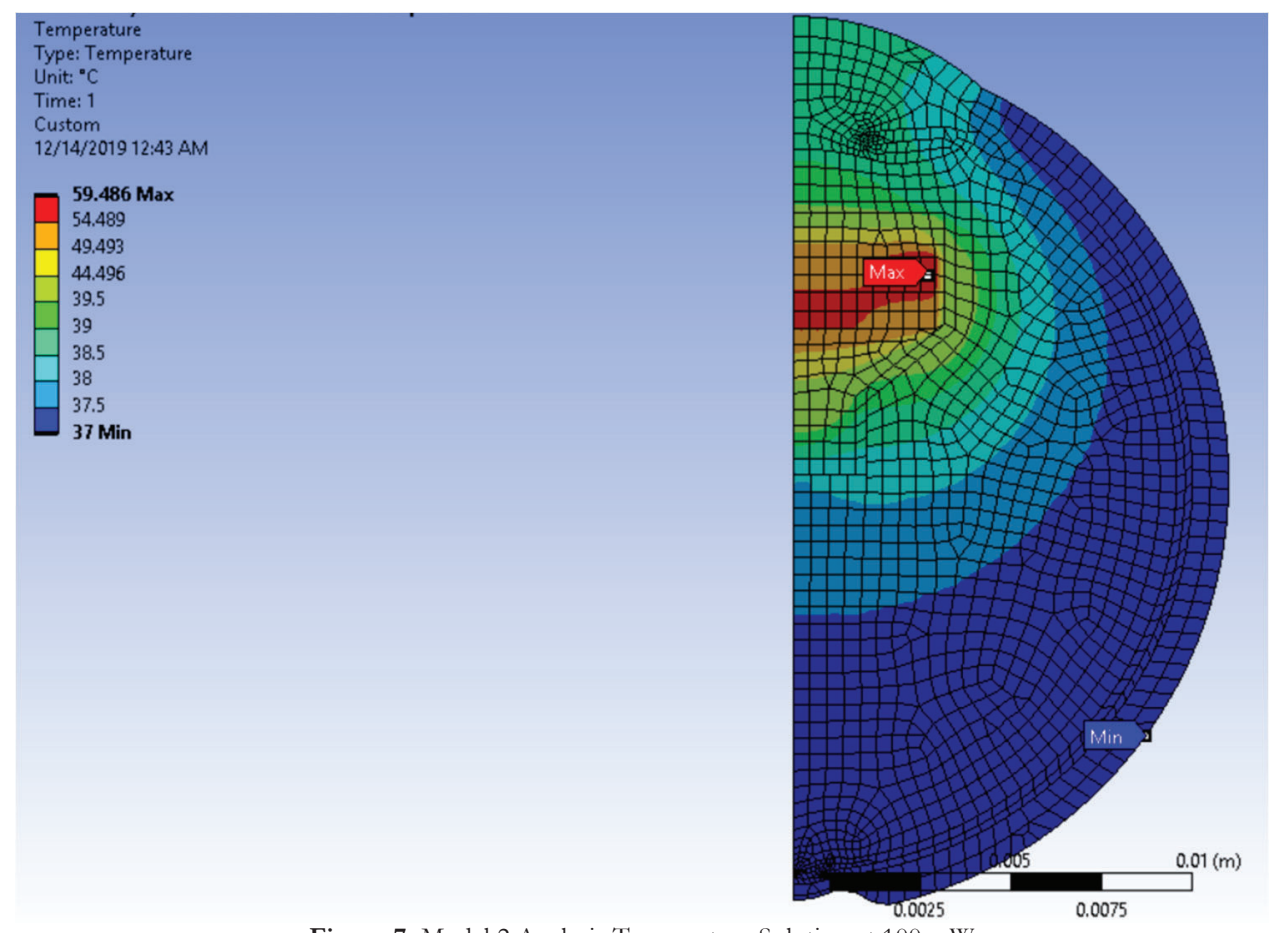

Figure 7. Model 2 Analysis Temperature Solution at $100 \mathrm{~mW}$

The final maximum temperatures of the iris for both Models are below in Table 3. As seen in the table, the maximum iris temperature at $100 \mathrm{~mW}$ for Model 1 exceeds $39^{\circ} \mathrm{C}$ by $0.002{ }^{\circ} \mathrm{C}$. For Model 2 , the iris temperature achieved a maximum of 38.766 ${ }^{\circ} \mathrm{C}$ which is below $39^{\circ} \mathrm{C}$ thereby not resulting in more than a $2{ }^{\circ} \mathrm{C}$ increase.

\begin{tabular}{|c|c|c|}
\hline Power $(\mathrm{mW})$ & Model 1 Max Iris Temperature $\left({ }^{\circ} \mathbf{C}\right)$ & Model 2 Max Iris Temperature $\left({ }^{\circ} \mathbf{C}\right)$ \\
\hline 25 & 38.006 & 37.928 \\
\hline 50 & 38.337 & 38.207 \\
\hline 75 & 38.67 & 38.486 \\
\hline 100 & 39.002 & 38.766 \\
\hline
\end{tabular}

Table 3. Maximum Iris Temperatures for Models 1 and 2 at $100 \mathrm{~mW}$

There is roughly a linear relationship between the wattage of the LED and the maximum temperature of the iris. This relationship is portrayed in a graph in Figure 8. 


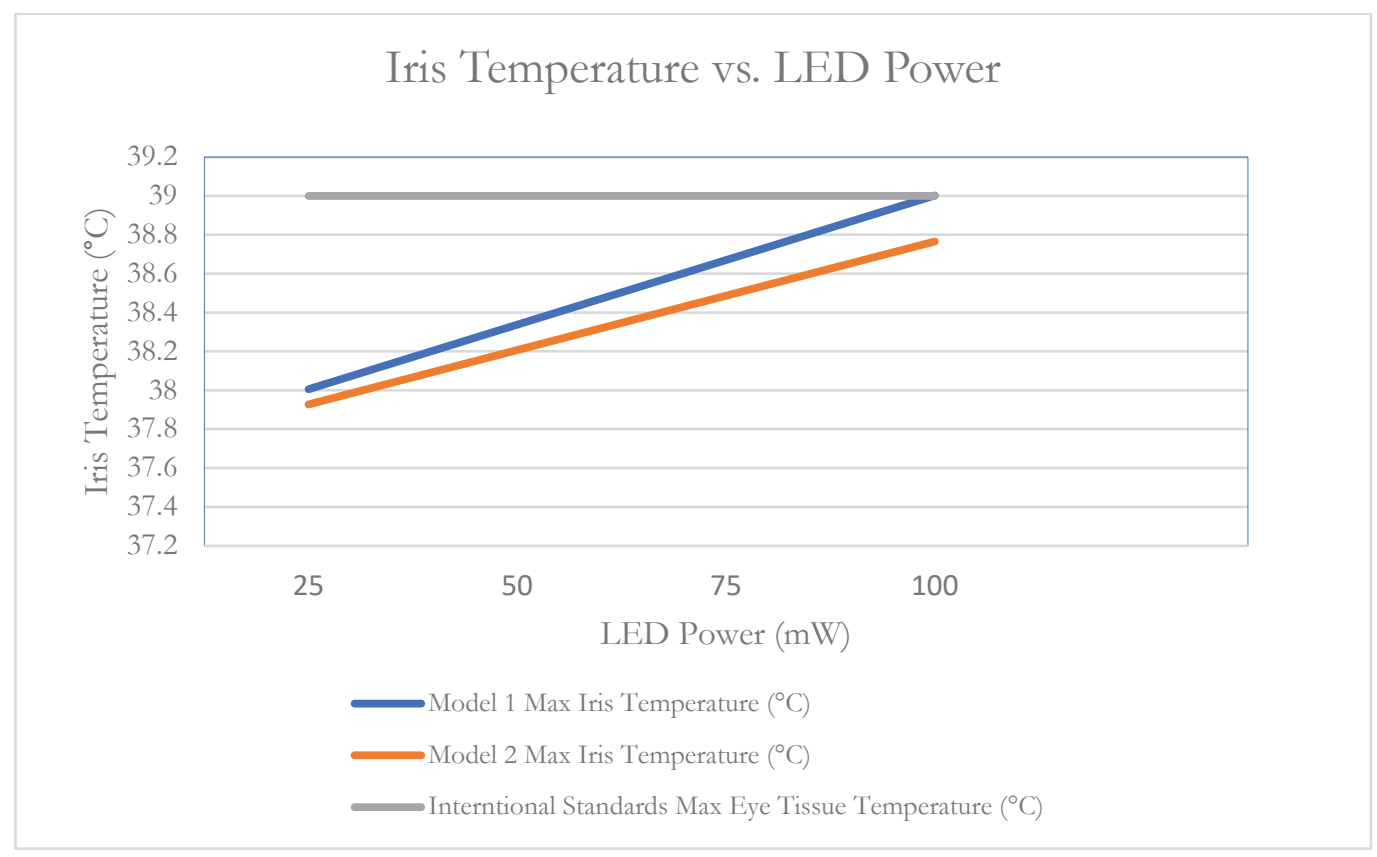

Figure 8. Graphical Representation of the Linear Relationship between Maximum Iris Temperature and LED Power

\section{CONCLUSIONS}

In this study, the temperature distribution across two $2 \mathrm{D}$ axisymmetric eye models were analyzed. AIMD standards have stated that a device, such as this intraocular projector, cannot cause more than a $2{ }^{\circ} \mathrm{C}$ increase in eye tissue temperature. Two Solidworks models were imported into ANSYS with specific boundary conditions to study if these standards were met. These two models consisted of one model with the original projector design, and another model including the second projector with an added 0.5 $\mathrm{mm}$ air gap. The two models were tested at $25 \mathrm{~mW}, 50 \mathrm{~mW}, 75 \mathrm{~mW}$, and $100 \mathrm{~mW}$ of power produced in the LED. Model 1 showed an increase of at least $2{ }^{\circ} \mathrm{C}$ for $100 \mathrm{~mW}$. Considering the camera works best at $100 \mathrm{~mW}$, because it outputs the best image onto the retina, Model 2 had a $0.5 \mathrm{~mm}$ air gap extension to insulate heat better within the camera. This caused temperatures of the iris to stay within $39^{\circ} \mathrm{C}$. Based upon this eye model with the $0.5 \mathrm{~mm}$ air gap, the intraocular projector can safely be operated with $100 \mathrm{~mW}$ of power from the LED.

\section{ACKNOWLEDGEMENTS}

The first author gratefully acknowledges support of the University of Illinois at Chicago College of Engineering Guaranteed Paid Internship Program. The authors would like to thank Dipika Gongal, Siddhant Tahkur, Ashay Panse, Rahul Pawar and Torna Patil for their help with dimensions of the eye model and guidance in the finite element analysis. This research is partially funded by US Department of Defense grant VR180058 and US NIH National Eye Institute grant K08EY27469, and that support is gratefully acknowledged.

\section{REFERENCES}

1. Whitcher, Srinivasan J. M., and Upadhyay, M. (2001) Corneal blindness: a global perspective, Bull World Health Organ., 214-221.

2. Tan, D., Dart, J., Holland, E. and Kinoshita, S. (2012) Corneal transplantation, The Lancet, 379(9827), 1749-1761. bttps:// doi.org/10.1016/s0140-6736(12)60437-1

3. Gain, P., et al., (2016) Global Survey of Corneal Transplantation and Eye Banking, JAMA Ophthalmology, 134(2), 167. bttps://doiorg/10.1001/jamaophthalmol.2015.4776

4. Yu, C. et al., (2019) Feasibility of Intraocular Projection for Treatment of Intractable Corneal Opacity, Cornea, 38(4), 523-527. bttps:// doi.org/10.1097/ico.0000000000001852

5. ISO 14708-1:2014, ISO, 2019. Available: https://www.iso.org/standard/52804.html. (Accessed: 26- Nov- 2019).

6. Scott, J. (1988) A finite element model of heat transport in the human eye, Physics in Medicine and Biology, 33(2), 227-242. bttps:// doi.org/10.1088/0031-9155/33/2/003

7. Scott, J. (1988) The computation of temperature rises in the human eye induced by infrared radiation, Physics in Medicine and Biology, 33(2), 243-257. bttps:/ / doi.org/10.1088/0031-9155/33/2/004

8. Shibib, K. (2012) Finite element analysis of cornea thermal damage due to pulse incidental far IR laser, Lasers in Medical Science, 28(3), 871-877. https:// doi.org/10.1007/s10103-012-1168-2 
9. Mirnezami, S. Rajaei Jafarabadi, M. and Abrishami, M., (2013) Temperature Distribution Simulation of the Human Eye Exposed to Laser Radiation, Journal of lasers in medical sciences, 4, 176-182. bttps:/ / doi.org/10.22037/jlms.v4i4.3928

10. Opie, N., Burkitt, A., Meffin, H., Grayden, D. (2012) Heating of the Eye by a Retinal Prosthesis: Modeling, Cadaver and In Vivo Study, IEEE Transactions on Biomedical Engineering, 59(2), 339-345. https:/ / doi.org/ 10.1109/tbme.2011.2171961

11. Gosalia, K., Weiland, J., Humayun, M., and Lazzi, G. (2004) Thermal Elevation in the Human Eye and Head Due to the Operation of a Retinal Prosthesis, IEEE Transactions on Biomedical Engineering, 51(8), 1469-1477. https:/ / doi.org/10.1109/tbme.2004.827548

12. Lazzi, G. (2005) Thermal effects of bioimplants, IEEE Engineering in Medicine and Biology Magazine, 24(5), 75-81. https:// doi.org/10.1109/memb.2005.1511503

13. Wessapan, T., and Rattanadecho, P. (2015) Heat Transfer Analysis of the Human Eye During Exposure to Sauna Therapy, Numerical Heat Transfer, Part A: Applications, 68(5), 566-582. https:/ / doi.org/ 10.1080/10407782.2014.986393

14. Rafiq, A., and Khanday, M. (2016) Thermal behavior of human eye in relation with change in blood perfusion, porosity, evaporation and ambient temperature, Journal of Thermal Biology, 62, 138-142. https://doi.org/10.1016/j.jtherbio.2016.06.024

15. Thompson, K., Bhardwaj, R., Nguyen, T. (2017) Development of an Anatomically Accurate Finite Element Human Ocular Globe Model for Blast-Related Fluid-Structure Interaction Studies. US Army Research Laboratory report ARL-TR-7945

16. Pawar, R. (2018) Design and Finite Element Analysis of effects of Therapeutic Hypothermia in Human Eye, University of Illinois at Chicago.

17. Wessapan, T., and Rattanadecho, P. (2015) Heat Transfer Analysis of the Human Eye During Exposure to Sauna Therapy, Numerical Heat Transfer, Part A: Applications, 68(5), 566-582. https:// doi.org/ 10.1080/10407782.2014.986393

18. Nayar, K., Sharqawy, M., Banchik, L., and Lienhard, J. (2016) Thermophysical properties of seawater: A review and new correlations that include pressure dependence, Desalination, 390, 1-24. https://doi.org/10.1016/j.desal.2016.02.024

19. Sharqawy, M., Lienhard, J., and Zubair, S. (2010) Thermophysical properties of seawater: a review of existing correlations and data, Desalination and Water Treatment, 16(1-3), 354-380. https:/ / doi.org/ 10.5004/ dwt.2010.1079

20. Assael, M., Botsios, S., Gialou, K., and Metaxa, I. (2005) Thermal Conductivity of Polymethyl Methacrylate (PMMA) and Borosilicate Crown Glass BK7, International Journal of Thermophysics, 26(5), 1595-1605. https:/ / doi.org/10.1007/s10765-005-8106-5

21. The Thermal Conductivity of Unfilled Plastics - C-Therm - Thermal Conductivity Instruments, https://ctherm.com/resources/blog/the_thermal_conductivity_of_unfilled_plastics/. (Accessed: 26- Nov- 2019).

\begin{abstract}
ABOUT THE AUTHORS
John Stark is a Junior Civil Engineering Student at the University of Illinois at Chicago (UIC) and plans on graduating with a bachelor's degree in May 2022. John has been working on this project since the summer of 2019 through the Guaranteed Paid Internship Program at UIC. He plans to continue researching the method of finite element analysis and develop a focus in structural engineering within his major.
\end{abstract}

Craig Foster is a professor of Civil and Materials Engineering at University of Illinois at Chicago. His research focuses on numerical modeling, especially finite element analysis, of mechanical, thermal, and multiphysics problems.

Charles Yu is an ophthalmologist at the Byers Eye Institute at Stanford University. His research focuses on medical devices for vision restoration.

\title{
PRESS SUMMARY
}

Corneal blindness continues to be a problem for millions of people across the world. An intraocular projector, also known as a micro-camera, is a novel proposed solution to this problem and is surgically placed inside the eye. The projector creates heat, which must be dissipated without causing damage to eye tissue. Australian and international standards state that there cannot be an increase of temperature of more than $2{ }^{\circ} \mathrm{C}$ from an implanted device; therefore, a simulation needs to be conducted to test if these standards are met. The eye and projector were designed in the CAD software, Solidworks, as a 2D axisymmetric model. The model was then analyzed in ANSYS Workbench finite element software to study the temperature change in the eye tissue as the projector is operating. 